\section{Cottage by the sea or house above the trees: which is better for my lungs?}

\author{
Andre F S Amaral, Jennifer K Quint
}

Lung function is better than systolic blood pressure in predicting all-cause mortality and surprisingly circulatory disease mortality. ${ }^{1}$ It is a strong predictor of shorter survival even among people who have never smoked and in those with no symptoms of lung disease. ${ }^{1-3}$ A lung function lower than normal is usually the result of poor lung development in early life or a rapid decline of lung function with age during adulthood or both. ${ }^{4-6}$

The best established risk factor for rapid decline in lung function is tobacco smoking, ${ }^{7}$ but obesity, occupational exposures and socioeconomic position-related factors may also play a key role. ${ }^{8-12}$ In addition, there is evidence showing that people with asthma or hypertension tend to see a faster deterioration of their lung function. ${ }^{513}$ However, most data on this topic come from studies carried out mainly in high-income countries bringing into question whether the same is true in low/middle-income countries, where the prevalence of tobacco smoking has been lower and other environmental factors may be of greater relevance.

Miele et $a l^{14}$ report findings of the CRONICAS study where they investigated whether prebronchodilator lung function is affected by factors such as urbanisation, altitude, use of biomass for cooking, asthma, chronic bronchitis, history of pulmonary $\mathrm{TB}$, hypertension, body mass index (BMI), diabetes and systemic C-reactive protein levels. This is a study of about 3000 adults from four sites in Peru who were followed up on average for 2.4 years, had performed spirometry up to three times and had been clinically assessed and provided information on several sociodemographic and lifestyle factors at baseline. The data were analysed using multivariable linear mixed effects models accounting for clustering within participants (ie, repeated measurements) but not by site.

Miele et $a l^{14}$ observed a mean annual decline of $30.3 \mathrm{~mL}$ in $\mathrm{FEV}_{1}$ and $32.2 \mathrm{~mL}$

Population Health and Occupational Disease, National Heart and Lung Institute, Imperial College London, London, UK

Correspondence to Dr Andre F S Amaral, Population Health and Occupational Disease, National Heart and Lung Institute, Imperial College London, London SW3 6LR, UK; a.amaral@imperial.ac.uk in FVC, which is in line with other population-based longitudinal studies, ${ }^{15} 16$ and found that a greater than average decline in lung function was associated with living in an urban setting, living at high altitude and hypertension. Interestingly they did not find a significant association of lung function decline with tobacco smoking or use of biomass for cooking.

Miele et $a l^{14}$ did not suggest a mechanism to explain the association with urbanisation, but they hinted at outdoor air pollution which is usually higher in urban centres. However, there might be a different reason. In the CRONICAS study, urban sites have the highest prevalence of asthma and in one of the two rural sites nobody has asthma. As a faster decline in lung function is associated with asthma, ${ }^{5}$ it is not unlikely that the association with urbanisation is driven by the higher prevalence of this disease in urban sites. Although the authors adjusted their models for asthma, they did not account for clustering by site and not all participants contributed to the analysis with the same number of spirometry measurements, thus it is possible that participants with asthma in urban areas were over-represented. Exclusion of participants with asthma in a sensitivity analysis would have been useful to investigate this suspicion.

A longitudinal study on altitude and lung function decline is welcome as several cross-sectional studies on 'COPD' and altitude have reported conflicting results. ${ }^{17}$ To support the association with high altitude, Miele et $a l^{14}$ pointed the finger at hypoxia-induced systemic inflammation generated in adipose tissue as the underlying mechanism. Yet, lung function decline was not associated with the levels of C-reactive protein, a marker of systemic inflammation, which were on average lower in the sites at high altitude. Since a high BMI has been associated with faster decline in lung function, ${ }^{812}$ could it be that the association with altitude in this study is driven by the higher prevalence of overweight and obese participants in the two sites at high altitude? An additional sensitivity analysis including only participants with normal BMI would have cleared this doubt.

The inverse association of lung function decline with hypertension reported by Miele et $a l^{14}$ is consistent with results from the Cardiovascular Health Study and the Coronary Artery Risk Development in Young Adults (CARDIA) study, both longitudinal studies with longer follow-ups, ${ }^{13} 18$ although in the CARDIA study hypertension was the outcome and lung function, that is, FVC, was the risk factor. As mentioned by the authors, several mechanisms have been proposed for this relationship, but none has been established yet. The most likely biological explanation for Miele $e t \mathrm{al}^{14}$ finding could reside in the degradation of arterial and lung parenchymal tissue elasticity occurring in parallel. ${ }^{19}$ However, more and larger longitudinal studies are needed to establish the direction of this relationship and its underlying mechanism.

The lack of association of lung function decline with tobacco smoking in this study could call into question the validity of the other findings. However, the low prevalence of daily tobacco smoking, and eventually low smoking intensity, could explain this null result. Another plausible reason for this result would be that at baseline smokers already had poor lung function, so they would not have much to lose during the brief period of time they were followed up.

The most surprising finding by Miele et $a l^{14}$ was the null association between lung function decline and use of biomass since the CRONICAS study have previously reported that female participants using biomass on a daily basis were 2.22 times more likely to have 'COPD' than those not using biomass. ${ }^{20}$ The authors suggest this finding might be due to the short follow-up time, but it could also be that there is no association or there is some other risk factor for rapid lung function decline that was not measured. Findings from recent large cross-sectional studies have not been supportive of such association. $^{21-23}$

Despite the several limitations of this study, Miele et $a l^{14}$ bring to the table several potential risk factors that have not been investigated much elsewhere and perhaps it is time for us to start thinking outside the box. Improving our understanding of lung function decline, especially for when it is too late to influence the growth and development of the lungs, is a vital step to improve lung health and the chances of living longer.

Contributors AFSA wrote the first draft, JKQ reviewed and both approved the final submission.

Funding The authors have not declared a specific grant for this research from any funding agency in the public, commercial or not-for-profit sectors. 
Competing interests None declared.

\section{Patient consent Not required.}

Provenance and peer review Commissioned; externally peer reviewed.

(c) Author(s) (or their employer(s)) 2018. No commercial re-use. See rights and permissions. Published by BMJ.

\section{A) Check for updates}

To cite Amaral AFS, Quint JK. Thorax 2018;73:1103-1104.

Accepted 21 August 2018

Published Online First 30 August 2018

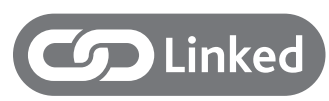

- http://dx.doi.org/10.1136/thoraxjnl-2017-210477

Thorax 2018:73:1103-1104.

doi:10.1136/thoraxjnl-2018-212146

\section{REFERENCES}

1 Gupta RP, Strachan DP. Ventilatory function as a predictor of mortality in lifelong non-smokers: evidence from large British cohort studies. BMJ Open 2017;7:e015381.

2 Schünemann HJ, Dorn J, Grant BJ, et al. Pulmonary function is a long-term predictor of mortality in the general population: 29-year follow-up of the Buffalo Health Study. Chest 2000;118:656-64.

3 Burney PG, Hooper R. Forced vital capacity, airway obstruction and survival in a general population sample from the USA. Thorax 2011;66:49-54.
4 Allinson JP, Hardy R, Donaldson GC, et al. Combined impact of smoking and early-life exposures on adult lung function trajectories. Am J Respir Crit Care Med 2017; 196:1021-30.

5 Bui DS, Lodge CJ, Burgess JA, et al. Childhood predictors of lung function trajectories and future COPD risk: a prospective cohort study from the first to the sixth decade of life. Lancet Respir Med 2018;6:535-44.

6 Tennant PW, Gibson GJ, Parker L, et al. Childhood respiratory illness and lung function at ages 14 and 50 years: childhood respiratory illness and lung function. Chest 2010;137:146-55.

7 Kohansal R, Martinez-Camblor P, Agustí A, et al. The natural history of chronic airflow obstruction revisited: an analysis of the Framingham offspring cohort. Am J Respir Crit Care Med 2009;180:3-10.

8 Bottai M, Pistelli F, Di Pede F, et al. Longitudinal changes of body mass index, spirometry and diffusion in a general population. Eur Respir J 2002;20:665-73.

9 de Jong K, Boezen HM, Kromhout $\mathrm{H}$, et al. Association of occupational pesticide exposure with accelerated longitudinal decline in lung function. Am J Epidemiol 2014:179:1323-30.

10 Liao SY, Lin X, Christiani DC. Occupational exposures and longitudinal lung function decline. Am J Ind Med 2015;58:14-20.

11 Ramsay SE, Whincup PH, Lennon LT, et al. Longitudinal associations of socioeconomic position in childhood and adulthood with decline in lung function over 20 years: results from a population-based cohort of British men. Thorax 2011;66:1058-64.

12 Thyagarajan B, Jacobs DR, Apostol GG, et al. Longitudinal association of body mass index with lung function: the CARDIA study. Respir Res 2008;9:31.

13 Griffith KA, Sherrill DL, Siegel EM, et al. Predictors of loss of lung function in the elderly: the cardiovascular health study. Am J Respir Crit Care Med 2001;163:61-8.
14 Miele CH, Grigsby MR, Siddharthan T, et al. CRONICAS Cohort Study Group. Environmental exposures and systemic hypertension are risk factors for decline in lung function. Thorax 2018;73:1120-7.

15 Kerstjens HA, Rijcken B, Schouten JP, et al. Decline of FEV 1 by age and smoking status: facts, figures, and fallacies. Thorax 1997;52:820-7.

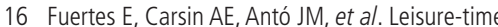
vigorous physical activity is associated with better lung function: the prospective ECRHS study. Thorax 2018;73:376-84.

17 Horner A, Soriano JB, Puhan MA, et al. Altitude and COPD prevalence: analysis of the PREPOCOL-PLATINOBOLD-EPI-SCAN study. Respir Res 2017;18:162.

18 Jacobs DR, Yatsuya H, Hearst MO, et al. Rate of decline of forced vital capacity predicts future arterial hypertension: the Coronary Artery Risk Development in Young Adults Study. Hypertension 2012:59:219-25.

19 Duprez DA, Hearst MO, Lutsey PL, et al. Associations among lung function, arterial elasticity, and circulating endothelial and inflammation markers: the multiethnic study of atherosclerosis. Hypertension 2013;61:542-8

20 Jaganath D, Miranda JJ, Gilman RH, et al. Prevalence of chronic obstructive pulmonary disease and variation in risk factors across four geographically diverse resource-limited settings in Peru. Respir Res 2015;16:40.

21 Amaral AFS, Patel J, Kato BS, et al. Airflow obstruction and use of solid fuels for cooking or heating: BOLD results. Am J Respir Crit Care Med 2018;197:595-610.

22 Fang L, Gao P, Bao H, et al. Chronic obstructive pulmonary disease in China: a nationwide prevalence study. Lancet Respir Med 2018;6:421-30.

23 Wang C, Xu J, Yang L, et al. Prevalence and risk factors of chronic obstructive pulmonary disease in China (the China Pulmonary Health [CPH] study): a national cross-sectional study. Lancet 2018;391:1706-17. 